\title{
A REPRESENTATION THEOREM FOR OPERATORS ON A SPACE OF INTERVAL FUNCTIONS
}

\author{
J. A. ChATFIELD \\ Department of Mathematics \\ Southwest Texas State University \\ San Marcos, Texas 78666 U.S.A.
}

(Received May 4, 1978)

ABSTRACT. Suppose $\mathrm{N}$ is a Banach space of norm $|\cdot|$ and $\mathrm{R}$ is the set of real numbers. All integrals used are of the subdivision-refinement type. The main theorem [Theorem 3] gives a representation of $\mathrm{TH}$ where $\mathrm{H}$ is a function from $\operatorname{RxR}$ to $\dot{\mathrm{N}}$ such that $\mathrm{H}\left(\mathrm{p}^{+}, \mathrm{p}^{+}\right), \mathrm{H}\left(\mathrm{p}, \mathrm{p}^{+}\right), \mathrm{H}\left(\mathrm{p}^{-}, \mathrm{p}^{-}\right)$, and $\mathrm{H}\left(\mathrm{p}^{-}, \mathrm{p}\right)$ each exist for each $\mathrm{p}$ and $\mathrm{T}$ is a bounded linear operator on the space of all such functions H. In particular we show that

$$
\begin{aligned}
\mathrm{TH}=(\mathrm{I}) \int_{\mathrm{a}}^{\mathrm{b}} \mathrm{f}_{\mathrm{H}} \mathrm{d} \alpha & +\sum_{i=1}^{\infty}\left[\mathrm{H}\left(\mathrm{x}_{1-1}, \mathrm{x}_{i-1}^{+}\right)-\mathrm{H}\left(\mathrm{x}_{i-1}^{+}, \mathrm{x}_{i-1}^{+}\right)\right] \beta\left(\mathrm{x}_{i-1}\right) \\
& +\sum_{i=1}^{\infty}\left[\mathrm{H}\left(\mathrm{x}_{i}^{-}, \mathrm{x}_{i}\right)-\mathrm{H}\left(\mathrm{x}_{i}^{-}, \mathrm{x}_{i}^{-}\right)\right] \Theta\left(\mathrm{x}_{i-1}, \mathrm{x}_{i}\right)
\end{aligned}
$$

where each of $\alpha, \beta$, and $\theta$ depend only on $\mathrm{T}, \alpha$ is of bounded variation, $\beta$ and $\Theta$ are 0 except at a countable number of points, $f_{H}$ is a function from $R$ to $N$ depending on $\mathrm{H}$, and $\left\{\mathrm{x}_{i}\right\}_{i=1}^{\infty}$ denotes the points $\mathrm{p}$ in $[\mathrm{a}, \mathrm{b}]$ for which $\left[\mathrm{H}\left(\mathrm{p}, \mathrm{p}^{+}\right)-\mathrm{H}\left(\mathrm{p}^{+}, \mathrm{p}^{+}\right)\right] \neq 0$ or $\left[\mathrm{H}\left(\mathrm{p}^{-}, \mathrm{p}\right)-\mathrm{H}\left(\mathrm{p}^{-}, \mathrm{p}^{-}\right)\right] \neq 0$. We also define an interior 
interval function integral and give a relationship between it and the standard interval function integral.

\section{INTRODUCTION.}

Let $\mathrm{N}$ be a Banach space of norm $|\cdot|$ and $\mathrm{R}$ the set of real numbers. The purpose of this paper is to exhibit a representation of $\mathrm{TH}$ where $\mathrm{H}$ is a function from $\operatorname{RxR}$ to $\mathrm{N}$ such that $\mathrm{H}\left(\mathrm{p}^{+}, \mathrm{p}^{+}\right), \mathrm{H}\left(\mathrm{p}, \mathrm{p}^{+}\right)$, and $\mathrm{H}\left(\mathrm{p}^{-}, \mathrm{p}^{-}\right)$, and $\mathrm{H}\left(\mathrm{p}^{-}, \mathrm{p}\right)$ each exist for each $\mathrm{p}$ and $\mathrm{T}$ is a bounded linear operator on the space of all such functions $\mathrm{H}$. Functions $\mathrm{H}$ for which each of the four preceding limits exist have been used extensively in the study of both sum integration and multiplicative integration, (for example see [2]). In particular we show that

$$
\begin{aligned}
\mathrm{TH}=(\mathrm{I}) \int_{\mathrm{a} \mathrm{f}^{\mathrm{d}} \mathrm{d}}^{\mathrm{b}} & +\sum_{i=1}^{\infty}\left[\mathrm{H}\left(\mathrm{x}_{i-1}, \mathrm{x}_{i-1}^{+}\right)-\mathrm{H}\left(\mathrm{x}_{i-1}^{+}, \mathrm{x}_{i-1}^{+}\right)\right] \beta\left(\mathrm{x}_{i-1}\right) \\
& +\sum_{i=1}^{\infty}\left[\mathrm{H}\left(\mathrm{x}_{i}^{-}, \mathrm{x}_{i}\right)-\mathrm{H}\left(\mathrm{x}_{i}^{-}, \mathrm{x}_{i}^{-}\right)\right] \Theta\left(\mathrm{x}_{i-1}, \mathrm{x}_{i}\right),
\end{aligned}
$$

where each of $\alpha, \beta, \theta$ depend only on $\mathrm{T}, \alpha$ is of bounded variation, $\beta$ and $\theta$ are 0 except at a countable number of points, $f_{H}$ is a function from $R$ to $\mathrm{N}$ depending on $\mathrm{H}$, and $\left\{\mathrm{x}_{\mathrm{i}}\right\}_{\mathrm{i}=1}^{\infty}$ denotes the points $\mathrm{p}$ in $[\mathrm{a}, \mathrm{b}]$ fur which $\mathrm{H}\left(\mathrm{p}, \mathrm{p}^{+}\right)-\mathrm{H}\left(\mathrm{p}^{+}, \mathrm{p}^{+}\right) \neq 0$ or $\left[\mathrm{H}\left(\mathrm{p}^{-}, \mathrm{p}\right)-\mathrm{H}\left(\mathrm{p}^{-}, \mathrm{p}^{-}\right)\right] \neq 0$. We also define an interior interval function integral and give a relationship between it and the standard interval function integral.

\section{DEFINITIONS.}

If $\mathrm{H}$ is a function from $\operatorname{RxR}$ to $\mathrm{N}$, then $\mathrm{H}\left(\mathrm{p}^{+}, \mathrm{p}^{+}\right)=1$ im $+\mathrm{H}(\mathrm{x}, \mathrm{y})$ and similar $x, y \rightarrow p$ meanings are given to $\mathrm{H}\left(\mathrm{p}, \mathrm{p}^{+}\right), \mathrm{H}\left(\mathrm{p}^{-}, \mathrm{p}^{-}\right)$, and $\mathrm{H}\left(\mathrm{p}^{-}, \mathrm{p}\right)$. The set of all functions for which each of the preceding four limits exist will be denoted by $\mathrm{OL}^{0}$. If $\mathrm{H}$ is a function from $\operatorname{RxR}$ to $\mathrm{N}$ then $\mathrm{H}$ is said to be (1) of bounded variation on the interval $[\mathrm{a}, \mathrm{b}]$ and (2) bounded on $[\mathrm{a}, \mathrm{b}]$ if there exists a number $M$ and $a$ subdivision $D$ of $[a, b]$ such that if $D^{\prime}=\left\{x_{i}\right\}_{i=0}^{n}$ is a refinement of $D$ then 
(1) $\sum_{i=1}^{n}\left|H\left(x_{i-1}, x_{i}\right)\right|<M$ and (2) if $0<i \leq n$, then $\left|H\left(x_{i-1}, x_{i}\right)\right|<M$, respectively. Further, $\mathrm{H}$ is said to be integrable on $[\mathrm{a}, \mathrm{b}]$ if there is a number $\mathrm{A}$ such that for each $\varepsilon>0$ there is a subdivision $D$ of $[a, b]$ such that if $D^{\prime}=\left\{x_{i}\right\}_{i=0}^{n}$ is a refinement of $D$, then $\left|\sum_{\substack{i=1 \\ D^{\prime}}}^{n} H\left(x_{i-1}, x_{i}\right)-A\right|<\varepsilon$ and $A$ is denoted by $\int_{a}^{b_{H}}$ when such an A exists. In our development we will also find a slight modification of the preceding definition useful. If $\mathrm{H}\left(\mathrm{x}_{i-1}, \mathrm{x}_{i}\right)$ is replaced by $\mathrm{H}\left(\mathrm{r}_{i}, \mathrm{~s}_{i}\right) \mathrm{G}\left(\mathrm{x}_{i-1}, \mathrm{x}_{i}\right)$, $x_{i-1}<r_{i}<s_{i}<x_{i}$, in the approximating sum of the preceding definition then the number $A$ is denoted by $\left(I_{H}\right) \int_{a}^{b} H G$ and termed the interior integral of $H$ with respect to $G$ on $[a, b]$. Also, if each of $f$ and $\alpha$ is a function from $R$ to $N$, then the interior integral of $\mathrm{f}$ with respect to $\alpha$ exists means there is a number A such that if $\varepsilon>0$ then there is a subdivision $D$ of $[a, b]$ such that if $D^{\prime}=\left\{x_{i}\right\}_{i=0}^{n}$ is a refinement of $D$ and for $0<i<n, x_{i-1}<t_{i}<x_{i}$, $\left|\sum_{\substack{i=1 \\ D^{\prime}}}^{n} f\left(t_{i}\right)\left[\alpha\left(x_{i}\right)-\alpha\left(x_{i-1}\right)\right]-A\right|<\varepsilon$ and $A$ is denoted by $(I) \int_{a}^{b} f d \alpha$. If $\alpha$ is a function from $R$ to $N, \alpha\left(p^{+}\right)=\lim _{x \rightarrow p^{+}} \alpha(x), \alpha\left(p^{-}\right)=\lim _{x \rightarrow p^{-}} \alpha(x)$, and $\mathrm{d} \alpha$ denotes the function $H$ from $\operatorname{RxR}$ to $N$ such that for $x<y, H(x, y)=\alpha(y)-\alpha(x)$. If each of $H, H_{1}, H_{2}$, . . is a function from $\operatorname{RxR}$ to $N$, then $\lim _{n \rightarrow \infty} H_{n}=H$ uniformly on $[\mathrm{a}, \mathrm{b}]$ means if $\varepsilon>0$ there is a positive integer $\mathrm{N}$ and a subdivision $\mathrm{D}=\left\{\mathrm{x}_{\mathrm{i}}\right\}_{i=0}^{\mathrm{n}}$ of $[\mathrm{a}, \mathrm{b}]$ such that if $\mathrm{n}>\mathrm{N}$ and $\mathrm{x}_{\mathrm{i}-1} \leq \mathrm{r}<\mathrm{s} \leq \mathrm{x}_{\mathrm{i}}$ for some $0<\mathrm{i} \leq \mathrm{n}$, then $\left|H(r, s)-H_{n}(r, s)\right|<\varepsilon$. If $H$ is a function from $R x R$ to $N$, then $H$ is bounded on $[a, b]$ means there is a number $M$ and a subdivision $D=\left\{x_{i}\right\}_{i=0}^{\infty}$ of $[a, b]$ such that if $0<i \leq n$ and $x_{i-1} \leq r<s \leq x_{i}$, then $|H(r, s)|<M$. The norm of $H$ on $[a, b]$ with respect to $D,\|H\|_{D}$ is then defined as the greatest lower bound of the set of all such M's. 
$\mathrm{T}$ is a linear operator on $\mathrm{OL}^{0}$ means $\mathrm{T}$ is a transformation from $\mathrm{OL}^{0}$ to $\mathrm{N}$ such that if each of $\mathrm{H}_{1}$ and $\mathrm{H}_{2}$ are in $\mathrm{OL}^{0}$ then

$$
\mathrm{T}\left[\mathrm{k}_{1} \mathrm{H}_{1}+\mathrm{k}_{2} \mathrm{H}_{2}\right]=\mathrm{k}_{1} \mathrm{TH}_{1}+\mathrm{k}_{2} \mathrm{TH}_{2}
$$

for $k_{1}, k_{2}$ in $R$. $T$ is bounded on $[a, b]$ means there is a number $M$ such that $|\mathrm{TH}| \leq \mathrm{M}|| \mathrm{H}||_{\mathrm{D}}$ for some subdivision $\mathrm{D}$ of $[\mathrm{a}, \mathrm{b}]$.

For convenience we adopt the following conventions for a function from RxR to $\mathrm{N}$ and $\mathrm{R}$ to $\mathrm{N}$ for some subdivision $\mathrm{D}=\left\{\mathrm{x}_{\mathrm{i}}\right\}_{\mathrm{i}=0}^{\mathrm{n}}$ of $[\mathrm{a}, \mathrm{b}]$ :

$$
\begin{aligned}
& \text { (1) } H\left(a^{-}, a\right)=H\left(a^{-}, a^{-}\right)=H\left(b, b^{+}\right)=H\left(b^{+}, b^{+}\right)=0, \\
& \text { (2) } H\left(x_{i-1}, x_{i}\right)=H_{i}, 0<i<n, \\
& \text { (3) } \alpha\left(x_{i}\right)-\alpha\left(x_{i-1}\right)=\Delta \alpha_{i}, \\
& \text { (4) } \sum_{i=1}^{n} H\left(x_{i-1}, x_{i}\right)=\sum_{D^{H}}{ }_{D} .
\end{aligned}
$$

\section{THEOREMS.}

We will begin by establishing a relationship between $\int_{a}^{b} H d \alpha$ and $\left(I_{H}\right) \int_{a}^{b} H d \alpha$ which will require the following lemmas.

LEMMA 1. If $\mathrm{H}$ is in $\mathrm{OL}^{0}$ and $\alpha$ is a function from $\mathrm{R}$ to $\mathrm{N}$ of bounded variation on $[a, b]$, then $\int_{a}^{b} H d \alpha$ exists.

This lemma is a special case of THEOREM 2 of [2].

LEMMA 2. Suppose $\mathrm{H}$ is in $\mathrm{OL}^{0},[\mathrm{a}, \mathrm{b}]$ is an interval, $\varepsilon>0$, and $\mathrm{S}_{1}$ and $\mathrm{S}_{2}$ are sets such that $\mathrm{p}$ is in $\mathrm{S}_{1}$ if and only if $\mathrm{p}$ is in $[\mathrm{a}, \mathrm{b}]$ and $\left|\mathrm{H}\left(\mathrm{p}, \mathrm{p}^{+}\right)-\mathrm{H}\left(\mathrm{p}^{+}, \mathrm{p}^{+}\right)\right| \geq \varepsilon$ and $\mathrm{p}$ is in $\mathrm{S}_{2}$ if and only if $\mathrm{p}$ is in $[\mathrm{a}, \mathrm{b}]$ and $\left|\mathrm{H}\left(\mathrm{p}^{-}, \mathrm{p}\right)-\mathrm{H}\left(\mathrm{p}^{-}, \mathrm{p}^{-}\right)\right| \geq \varepsilon$. Then, each of $\mathrm{s}_{1}$ and $S_{2}$ is a finite set. [2, lemma page 498].

We note that it follows from LEMMA 2 that if $S$ is the set such that $p$ is in $S$ if and only if $\mathrm{H}\left(\mathrm{p}, \mathrm{p}^{+}\right)-\mathrm{H}\left(\mathrm{p}^{+}, \mathrm{p}^{+}\right) \neq 0$ or $\mathrm{H}\left(\mathrm{p}^{-}, \mathrm{p}\right)-\mathrm{H}\left(\mathrm{p}^{-}, \mathrm{p}^{-}\right) \neq 0$ then $\mathrm{S}$ is countable:

LEMMA 3. If $\mathrm{H}$ is in $\mathrm{OL}^{0}$ and $\alpha$ is a function from $\mathrm{R}$ to $\mathrm{N}$ of bounded variation on $[a, b]$ then (1) if $p$ is in $[a, b]$ each of $\alpha\left(p^{+}\right)$and $\alpha\left(p^{-}\right)$exists and (2) if $\left\{x_{i}\right\}_{i=1}^{\infty}$ is a sequence of numbers such that if $\mathrm{p}$ is in $[\mathrm{a}, \mathrm{b}]$ and $\mathrm{H}\left(\mathrm{p}, \mathrm{p}^{+}\right)-\mathrm{H}\left(\mathrm{p}^{+}, \mathrm{p}^{+}\right) \neq 0$ 
or $\mathrm{H}\left(\mathrm{p}^{-}, \mathrm{p}\right)-\mathrm{H}\left(\mathrm{p}^{-}, \mathrm{p}^{-}\right) \neq 0$, then there is an $\mathrm{n}$ such that $\mathrm{p}=\mathrm{x}_{\mathrm{n}}$, then

(1) $\sum_{i=1}^{\infty}\left[\mathrm{H}\left(\mathrm{x}_{i}, \mathrm{x}_{i}^{+}\right)-\mathrm{H}\left(\mathrm{x}_{i}^{+}, \mathrm{x}_{i}^{+}\right)\right]\left[\alpha\left(\mathrm{x}_{i}^{+}\right)-\alpha\left(\mathrm{x}_{i}\right)\right]$ exists

and (2) $\sum_{i=1}^{\infty}\left[H\left(x_{i}^{-}, x_{i}\right)-H\left(x_{i}^{-}, x_{i}^{-}\right)\right]\left[\alpha\left(x_{i}^{-}\right)-\alpha\left(x_{i}\right)\right]$ exists.

INDICATION OF PROOF. It follows from the bounded variation of $\alpha$ that for $\mathrm{p}$ in $[\mathrm{a}, \mathrm{b}]$ each of $\alpha\left(\mathrm{p}^{+}\right)$and $\alpha\left(\mathrm{p}^{-}\right)$exists.

Since $\mathrm{H}$ is in $\mathrm{OL}^{0}$, it follows from the covering theorem that $\mathrm{H}$ is bounded on $[a, b]$ and that there is a number $M_{1}$ such that for each positive integer 1 ,

$$
\left|\mathrm{H}\left(\mathrm{x}_{i}, \mathrm{x}_{i}^{+}\right)-\mathrm{H}\left(\mathrm{x}_{i}^{+}, \mathrm{x}_{i}^{+}\right)\right|<\mathrm{M}_{1} \text {, }
$$

and, furthermore, for $n$ a positive integer and $0<i \leq n$, let $x_{p_{i}}>x_{i}$ such that $\sum_{i=1}^{n}\left|\alpha\left(x_{i}^{+}\right)-\alpha\left(x_{p_{i}}\right)\right|<1$. Hence,

$$
\begin{aligned}
& \sum_{i=1}^{n}\left|\left[H\left(x_{i}, x_{i}^{+}\right)-H\left(x_{i}^{+}, x_{i}^{+}\right)\right]\left[\alpha\left(x_{i}^{+}\right)-\alpha\left(x_{i}\right)\right]\right| \\
& \quad \leq M_{1}\left[\sum_{i=1}^{n}\left|\alpha\left(x_{i}^{+}\right)-\alpha\left(x_{p_{i}}\right)\right|+\sum_{i=1}^{n}\left|\alpha\left(x_{p_{i}}\right)-\alpha\left(x_{i}\right)\right|\right. \\
& \quad<M_{1}(1)+M_{1} \sum_{D}\left|\alpha\left(x_{i}\right)-\alpha\left(x_{i-1}\right)\right|,
\end{aligned}
$$

where $D$ is a subdivision of $[a, b]$ containing $x_{i}$ and $x_{p_{i}}$ as consecutive points in $D$ for each $0<i \leq n$. Hence, since $\alpha$ is of bounded variation there is a number M such that

$$
\sum_{i=1}^{n}\left|\left[H\left(x_{i}, x_{i}^{+}\right)-H\left(x_{i}^{+}, x_{i}^{+}\right)\right]\left[\alpha\left(x_{i}^{+}\right)-\alpha\left(x_{i}\right)\right]\right|<M .
$$

Therefore,

$$
\sum_{i=1}^{\infty}\left[H\left(x_{i}, x_{i}^{+}\right)-H\left(x_{i}^{+}, x_{i}^{+}\right)\right]\left[\alpha\left(x_{i}^{+}\right)-\alpha\left(x_{i}\right)\right] \text { exists. In a similar manner it may be }
$$
shown that

$$
\sum_{i=1}^{\infty}\left[H\left(x_{i}^{-}, x_{i}\right)-H\left(x_{i}^{-}, x_{i}^{-}\right)\right]\left[\alpha\left(x_{i}^{-}\right)-\alpha\left(x_{i}\right)\right] \text { exists. }
$$

THEOREM 1. If $\mathrm{H}$ is in $\mathrm{OL}^{0}$ and $\alpha$ is a function from $\mathrm{R}$ to $\mathrm{N}$ of bounded variation on $[\mathrm{a}, \mathrm{b}]$, then $\left(\mathrm{I}_{\mathrm{H}}\right) \int_{\mathrm{a}}^{\mathrm{b}} \mathrm{Hd} \alpha$ exists. 
PROOF. If $\varepsilon>0$ then it follows from LEMMA 2 that each of the sets $A_{\varepsilon}^{+}$and $\mathrm{A}_{\varepsilon}^{-}$to which $\mathrm{p}$ belongs if and only if $\mathrm{p}$ is in $[\mathrm{a}, \mathrm{b}]$ and $\left|\mathrm{H}\left(\mathrm{p}, \mathrm{p}^{+}\right)-\mathrm{H}\left(\mathrm{p}^{+}, \mathrm{p}^{+}\right)\right| \geq \varepsilon$ or $\left|\mathrm{H}\left(\mathrm{p}^{-}, \mathrm{p}\right)-\mathrm{H}\left(\mathrm{p}^{-}, \mathrm{p}^{-}\right)\right| \geq \varepsilon$, respectively, is a finite set. Let $\mathrm{A}_{\varepsilon}^{+}=\left\{\mathrm{c}_{i}\right\}_{i=1}^{\mathrm{m}_{1}}$, $A_{\varepsilon}^{-}=\left\{d_{i}\right\}_{i=1}^{m}$, and $A^{+}$and $A^{-}$denote the sets to which $p$ belongs if and on $1 y$ if $\mathrm{p}$ is in $[\mathrm{a}, \mathrm{b}]$ and $\mathrm{H}\left(\mathrm{p}, \mathrm{p}^{+}\right)-\mathrm{H}\left(\mathrm{p}^{+}, \mathrm{p}^{+}\right) \neq 0$ or $\mathrm{H}\left(\mathrm{p}^{-}, \mathrm{p}\right)-\mathrm{H}\left(\mathrm{p}^{-}, \mathrm{p}^{-}\right) \neq 0$, respectively. Since each of $A^{+}$and $A^{-}$is a countable set then let $A^{+}+A^{-}=\left\{y_{i}\right\}_{i=1}^{\infty}$.

Since $\alpha$ is of bounded variation on $[a, b]$, then for each $c_{i}, 0<i \leq m_{1}$ and $d_{i}, 0<i \leq m_{2}$ there is an $e_{i}>c_{i}$ and an $f_{i}>d_{i}$ such that if $e_{i} \geq r_{i}>c_{i}$ and and $\mathrm{f}_{i} \leq \mathrm{s}_{i}<\mathrm{d}_{i}$, then $\left|\alpha\left(\mathrm{c}_{i}^{+}\right)-\alpha\left(\mathrm{r}_{i}\right)\right|<\frac{\varepsilon}{16 \mathrm{~m}_{1}}$ and $\left|\alpha\left(\mathrm{d}_{i}^{-}\right)-\alpha\left(\mathrm{s}_{i}\right)\right|<\frac{\varepsilon}{16 \mathrm{~m}_{2}}$.

From LEMMA 3, it follows that there is a positive integer $N$ such that if $n>N$, then

(1) $\mid \sum_{i=1}^{n}\left[H\left(y_{i}, y_{i}^{+}\right)-H\left(y_{i}^{+}, y_{i}^{+}\right)\right]\left[\alpha\left(y_{i}^{+}\right)-\alpha\left(y_{i}\right)\right]$

$$
-\sum_{i=1}^{\infty}\left[H\left(y_{i}, y_{i}^{+}\right)-H\left(y_{i}^{+}, y_{i}^{+}\right)\right]\left[\alpha\left(y_{i}^{+}\right)-\alpha\left(y_{i}\right)\right] \mid<\frac{\varepsilon}{8}
$$

and

$$
\text { (2) } \begin{aligned}
\mid \sum_{i=1}^{n}[ & {\left[H\left(y_{i}^{-}, y_{i}\right)-H\left(y_{i}^{-}, y_{i}^{-}\right)\right]\left[\alpha\left(y_{i}^{-}\right)-\alpha\left(y_{i}\right)\right] } \\
& -\sum_{i=1}^{\infty}\left[H\left(y_{i}^{-}, y_{i}\right)-H\left(y_{i}^{-}, y_{i}^{-}\right)\right]\left[\alpha\left(y_{i}^{-}\right)-\alpha\left(y_{i}\right)\right] \mid<\frac{\varepsilon}{8} .
\end{aligned}
$$

Note that for some $y_{i}^{\prime} s,\left[H\left(y_{i}^{-}, y_{i}\right)-H\left(y_{i}^{-}, y_{i}^{-}\right)\right]$or $\left[H\left(y_{i}, y_{i}^{+}\right)-H\left(y_{1}^{+}, y_{1}^{+}\right)\right]$may be zero.

Since, from LEMMA $1, \int_{a}^{b} H d \alpha$ exists, then there is a number $M$ and a subdivision $D_{1}$ of $[a, b]$ such that if $D^{\prime}=\left\{x_{i}\right\}_{i=0}^{n}$ is a refinement of $D_{1}$, then

(3) $\sum_{D^{\prime}}\left|\Delta \alpha_{i}\right|<M$,

(4) $\left|\int_{a^{b}}^{b} \mathrm{Hd} \alpha-\sum_{D^{\prime}} H_{1} \Delta \alpha_{i}\right|<\frac{\varepsilon}{4}$,

and (5) if $0<i \leq n$, then $\left|H\left(x_{i-1}, x_{i-1}^{+}\right)-H\left(x_{i-1}^{+}, x_{i-1}^{+}\right)\right|<M$ and

$$
\left|\mathrm{H}\left(\mathrm{x}_{\bar{i}}^{-}, \mathrm{x}_{\mathbf{i}}\right)-\mathrm{H}\left(\mathrm{x}_{\mathbf{i}}^{-}, \mathrm{x}_{\mathbf{i}}^{-}\right)\right|<\mathrm{M} \text {. }
$$

Further, since $\mathrm{H}$ is in $\mathrm{OL}^{0}$, using the covering theorem we may obtain a subdivision $D_{2}$ of $[a, b]$ such that if $D^{\prime}=\left\{x_{i}\right\}_{i=0}^{n}$ is a refinement of $D_{2}, 0<i \leq n$, and 
$x_{i-1}<r<s<x_{i}$, then

(6) $\left|H(r, s)-H\left(x_{i}^{-}, x_{i}^{-}\right)\right|<\frac{\varepsilon}{64 M}$,

(7) $\left|H(r, s)-H\left(x_{i-1}, x_{i-1}\right)\right|<\frac{\varepsilon}{6 M}$,

(8) $\left|\mathrm{H}\left(\mathrm{x}_{i-1}, \mathrm{x}_{i-1}^{+}\right)-\mathrm{H}\left(\mathrm{x}_{i-1}, \mathrm{x}_{i}\right)\right|<\frac{\varepsilon}{64}$,

and (9) $\left|H\left(x_{i}^{-}, x_{i}\right)-H\left(x_{i-1}, x_{i}\right)\right|<\frac{\varepsilon}{64 M}$,

Let $D=D_{1}+D_{2}+A_{\varepsilon}^{+}+A_{\varepsilon}^{-}+\sum_{i=1}^{m_{1}}\left\{e_{i}\right\}+\sum_{i=1}^{m}\left\{f_{i}\right\}+\sum_{i=1}^{N}\left\{y_{i}\right\}, D^{\prime}=\left\{x_{i}\right\}_{i=0}^{n}$ be a refinement of $D$, and for each $0<i \leq n, x_{i-1}<r_{j-1}<s_{j}<x_{i}$. Choose $m>N$ such that for each $x_{i}, 0<i \leq n$, in $D^{\prime} \cdot\left(A^{+}+A^{-}\right)$there exists a positive integer $z<m$ such that $y_{z}=x_{i}$. Hence, for $x_{i}, 0<i \leq n$, in $D^{\prime}$ such that neither $x_{i-1}$ nor $x_{i}$ is in $\left(A^{+}+A^{-}\right)$, it follows from (6)-(9) that $\left|H\left(r_{i}, s_{i}\right)-H\left(x_{i-1}, x_{i}\right)\right|<\frac{\varepsilon}{32 M}$.

If $\mathrm{W}_{i}=\mathrm{H}\left(\mathrm{y}_{i-1}, \mathrm{y}_{i-1}^{+}\right)-\mathrm{H}\left(\mathrm{y}_{i-1}^{+}, \mathrm{y}_{i-1}^{+}\right)$and $\mathrm{Q}=\left\{\mathrm{y}_{1}, \mathrm{y}_{2}, \ldots \mathrm{y}_{\mathrm{m}}\right\}$ for $0<\mathrm{i} \leq \mathrm{m}$ then $\left|\sum_{i=1}^{m} W_{i}\left[\alpha\left(y_{i-1}^{+}\right)-\alpha\left(y_{i-1}\right)\right]-\sum\left[H\left(x_{i-1}, x_{i-1}^{+}\right)-H\left(x_{i-1}^{+}, x_{i-1}^{+}\right)\right] \Delta \alpha_{i}\right|$

$$
D^{\prime} \cdot\left[A_{\varepsilon}^{+}+\left(A^{+}-A_{\varepsilon}^{+}\right)\right]
$$

$=\left.\right|_{\varepsilon} ^{\mid \mathrm{A}_{\varepsilon}^{+}} \mathrm{W}_{1}\left[\alpha\left(\mathrm{y}_{\mathrm{i}-1}^{+}\right)-\alpha\left(\mathrm{y}_{\mathrm{i}-1}\right)\right]+\sum_{\mathrm{Q}-\mathrm{A}_{\varepsilon}^{+}} \mathrm{W}_{1}\left[\alpha\left(\mathrm{y}_{\mathrm{i}-1}^{+}\right)-\alpha\left(\mathrm{y}_{\mathrm{i}-1}\right)\right]$

$$
\begin{aligned}
& -\sum^{D^{\prime} \cdot \mathrm{A}_{\varepsilon}^{+}}\left[\mathrm{H}\left(\mathrm{x}_{\mathrm{i}-1}, \mathrm{x}_{i-1}^{+}\right)-\mathrm{H}\left(\mathrm{x}_{\mathrm{i}-1}^{+}, \mathrm{x}_{i-1}^{-}\right)\right] \Delta \alpha_{i} \\
& -\sum^{\sum}\left[\mathrm{H}\left(\mathrm{x}_{j-1}, \mathrm{x}_{i-1}^{+}\right)-\mathrm{H}\left(\mathrm{x}_{i-1}^{+}, \mathrm{x}_{i-1}^{+}\right)\right] \Delta \alpha_{i} \mid
\end{aligned}
$$

$\leq \sum_{A_{\varepsilon}^{+}}\left|W_{i}\right| \cdot\left|\alpha\left(y_{i-1}^{+}\right)-\alpha\left(y_{i}\right)\right|+\sum_{-} A_{\varepsilon}^{+}\left|W_{i}\right| \cdot\left|\alpha\left(y_{i-1}^{+}\right)-\alpha\left(y_{i-1}\right)\right|$

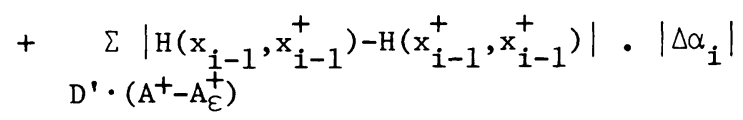

$<\mathrm{M} \sum_{\mathrm{A}_{\varepsilon}^{+}} \frac{\varepsilon}{16 \mathrm{Mm}_{1}}+\frac{\varepsilon}{16 \mathrm{M}} \sum_{\mathrm{Q}-\mathrm{A}_{\varepsilon}^{+}}\left|\alpha\left(\mathrm{y}_{\mathrm{i}-1}^{+}\right)-\alpha\left(\mathrm{y}_{\mathrm{i}-1}\right)\right|+\frac{\varepsilon}{16 \mathrm{M}} \sum^{\prime} \cdot\left(\mathrm{A}^{+}-\mathrm{A}_{\varepsilon}^{+}\right)$ $<\frac{3 \varepsilon}{16}$.

Hence 
(10) $\left|\sum_{i=1}^{\mathrm{m}} \mathrm{w}_{i}\left[\alpha\left(\mathrm{y}_{i-1}^{+}\right)-\alpha\left(\mathrm{y}_{i-1}\right)\right]-\sum_{\mathrm{D}^{\prime} \cdot \mathrm{A}^{+}} \mathrm{H}\left(\mathrm{x}_{\mathrm{i}-1}, \mathrm{x}_{\mathrm{i}-1}^{+}\right)-\mathrm{H}\left(\mathrm{x}_{\mathrm{i}-1}^{+}, \mathrm{x}_{\mathrm{i}-1}^{+}\right) \Delta \alpha_{i}\right|<\frac{3 \varepsilon}{16}$

and in a similar manner it may be shown that

(11) $\left|\sum_{i-1}^{m} z_{i}\left[\alpha\left(y_{i}^{-}\right)-\alpha\left(y_{i}\right)\right]-\sum_{D^{\prime} \cdot A^{-}}\left[H\left(x_{i}^{-}, x_{i}^{-}\right)-H\left(x_{i}^{-}, x_{i}\right)\right] \Delta \alpha_{i}\right|<\frac{3 \varepsilon}{16}$,

where $z_{i}=H\left(y_{i}^{-}, y_{i}^{-}\right)-H\left(y_{i}^{-}, y_{i}\right)$.

Using inequalities (10) and (11) we are now able to complete the proof of the theorem. In the following manipulations $\mathrm{w}_{i}$ and $\mathrm{z}_{i}$ are as defined for (10) and (11) and $P_{i}=H\left(x_{i-1}, x_{i-1}^{+}\right)-H\left(x_{i-1}^{+}, x_{i-1}^{+}\right)$and $Q_{i}=H\left(x_{i}^{-}, x_{i}^{-}\right)-H\left(x_{i}^{-}, x_{i}\right)$.

$$
\begin{aligned}
& \left|\sum_{D^{\prime}} H_{j} \Delta \alpha_{i}-\int_{a}^{b} H d \alpha-\sum_{i=1}^{\infty} W_{i}\left[\alpha\left(P_{i-1}^{+}\right)-\alpha\left(P_{i-1}\right)\right]-\sum_{i=1}^{\infty} z_{i}\left[\alpha\left(y_{i}^{-}\right)-\alpha\left(y_{i}\right)\right]\right| \\
& <\left|\sum_{D^{\prime}}\left(H_{j}-H_{i}\right) \Delta \alpha_{i}-\sum_{i=1} w_{i}\left[\alpha\left(y_{i-1}^{+}\right)-\alpha\left(y_{i-1}\right)\right]-\sum_{i=1}^{m} z_{i}\left[\alpha\left(y_{i}^{-}\right)-\alpha\left(y_{i}\right)\right]\right|+\frac{\varepsilon}{4}+\frac{\varepsilon}{16}+\frac{\varepsilon}{16} \\
& \leq\left|\sum_{D^{\prime}}\left(H_{j^{-}}-H_{i}\right) \Delta \alpha_{i^{-}} \sum_{D^{\prime} \cdot A^{+}} P_{i^{-}} \Delta \alpha_{i^{-}} \sum_{D^{\prime} \cdot A^{-}} Q_{i^{-1}} \Delta \alpha_{i}\right|+\frac{3}{16}+\frac{3}{16}+\frac{3}{8} \\
& \leq \underset{D^{\prime}-D^{\prime} \cdot\left(A^{+}+A^{-}\right)}{\sum\left|H_{i}-H_{i}\right|} \cdot\left|\Delta \alpha_{i}\right|+A_{j^{+}}-H_{i}-P_{i}\left|\Delta \alpha_{i}+\sum\right| H_{j}-H_{i}-Q_{i}|\cdot| \Delta \alpha_{i} \mid+\frac{3 \varepsilon}{4} \\
& <\frac{\varepsilon}{32 M} \cdot M+\frac{\varepsilon}{32 M} \cdot M+\frac{\varepsilon}{32 M} \cdot M \\
& <\varepsilon \text {. }
\end{aligned}
$$

Hence, we have a relationship established between $\left(I_{H}\right) \int_{a}^{b} H d \alpha$ and $\int_{a}^{b} H d \alpha$ which will be used in the proof of the principal theorem.

THEOREM 2. If $\left\{\mathrm{H}_{i}\right\}_{i=0}^{\infty}$ is a sequence of functions from $\mathrm{SxS}$ to $\mathrm{N}$, such that for each $i, H_{i}$ is in $O L^{0}, \lim _{n \rightarrow \infty} H_{n}=H_{0}$ uniformly on $[a, b]$, and $T$ is a bounded linear operator on $\mathrm{OL}^{0}$ then $\lim _{\mathrm{n} \rightarrow \infty} \mathrm{TH}_{\mathrm{n}}=\mathrm{TH}_{0}$.

The proof of this theorem is straightforward and we omit it.

THEOREM 3. Suppose $\mathrm{H}$ is in $\mathrm{OL}^{0}, \mathrm{~T}$ is a bounded linear operator on $\mathrm{OL}^{0}$. Then,

$$
\begin{aligned}
\mathrm{TH}= & (\mathrm{I}) \int_{\mathrm{a}}^{\mathrm{b}} \mathrm{f}_{\mathrm{H}} \mathrm{d} \alpha+\sum_{i=1}^{\infty}\left[\mathrm{H}\left(\mathrm{x}_{\mathrm{i}-1}, \mathrm{x}_{i-1}^{+}\right)-\mathrm{H}\left(\mathrm{x}_{i-1}^{+}, \mathrm{x}_{i-1}^{+}\right)\right] \beta\left(\mathrm{x}_{i-1}\right) \\
& +\sum_{i=1}^{\infty}\left[\mathrm{H}\left(\mathrm{x}_{\mathbf{i}}^{-}, \mathrm{x}_{\mathbf{i}}\right)-\mathrm{H}\left(\mathrm{x}_{\mathrm{i}}^{-}, \mathrm{x}_{i}^{-}\right)\right] \Theta\left(\mathrm{x}_{i-1}, \mathrm{x}_{\mathbf{i}}\right),
\end{aligned}
$$


where each of $\alpha, \beta$, and $\theta$ depend only on $\mathrm{T}, \alpha$ is of bounded variation, $\beta$ and $\theta$ are 0 except at a countable number of points, $f_{H}$ is a function from $R$ to $N$ depending on $H$, and $\left\{x_{i}\right\}_{i=1}^{\infty}$ denote the points in $[a, b]$ for which $\left[\mathrm{H}\left(\mathrm{x}_{i}, \mathrm{x}_{i}^{+}\right)-\mathrm{H}\left(\mathrm{x}_{i}^{+}, \mathrm{x}_{i}^{+}\right)\right] \neq 0$ or $\mathrm{H}\left(\mathrm{x}_{i}^{-}, \mathrm{x}_{i}\right)-\mathrm{H}\left(\mathrm{x}_{i}^{-}, \mathrm{x}_{i}^{-}\right) \neq 0, i=1,2, \ldots, \mathrm{n}$.

PROOF. We first define a sequence of functions converging uniformly to a given function $\mathrm{H}$ in $\mathrm{OL}^{0}$ and then apply THEOREM 2 to establish THEOREM 3 . We first define functions $g$ and $h$ for each pair of numbers $t, x, a \leq t \leq b, a \leq x \leq b$ such that

$$
g(t, x)=\left\{\begin{array}{l}
1, \text { if } t=x \\
0, \text { if } t \neq x
\end{array} \quad \text { and } h(t, x)=\left\{\begin{array}{l}
1, \text { if } a \leq t \leq x \\
0, \text { if } x<t \leq b,
\end{array}\right.\right.
$$

and using these functions and the operator $T$ define functions $\alpha, \beta, \gamma$, and $\emptyset$ such that

$$
\begin{aligned}
& \alpha(\mathrm{x})=\mathrm{TH}(\cdot, \mathrm{x}) ; \beta(\mathrm{x})=\mathrm{Tg}(\cdot, \mathrm{x}) ; \gamma(\mathrm{x})=\mathrm{Tg}(\mathrm{x}, \cdot) ; \emptyset(\mathrm{x}, \mathrm{y})=\mathrm{Tg}(\cdot, \mathrm{x}) \mathrm{g}(\mathrm{y}, \cdot) \text {; and } \\
& \Theta(x, y)=\gamma(y)-\emptyset(x, y) \text { for } x \text { and } y \text { in }[a, b] \text {. } \\
& \text { Clearly, } \alpha \text { is of bounded variation on }[a, b] \text { and we see from } \\
& \sum_{D^{\prime}}\left|\emptyset\left(x_{i-1}, x_{i}\right)\right|=\sum_{D^{\prime}} \emptyset_{i}^{2} \\
& =\sum_{D^{\prime}} \operatorname{sgn} \emptyset_{i} \operatorname{Tg}\left(\cdot, x_{i-1}\right) g\left(x_{1}, \cdot\right) \\
& \leq M|| \sum_{D^{\prime}} \operatorname{sgn} \emptyset_{i} g\left(\cdot, x_{i-1}\right) g\left(x_{i}, \cdot\right)||_{D} \\
& =\mathrm{M} \text {, }
\end{aligned}
$$

for $D^{\prime}$ a refinement of a subdivision $D$ of $[a, b]$, it follows that $\sum_{i=1}^{\infty}\left|\emptyset\left(x_{1-1}, x_{i}\right)\right|$ exists and in a similar manner that each of $\sum_{i=1}^{\infty}\left|\beta\left(x_{i}\right)\right|$ and $\sum_{i=1}^{\infty}\left|\left(x_{i}\right)\right|$ exists. Hence, $\sum_{i=1}^{\infty}\left|\theta\left(x_{i-1}, x_{i}\right)\right|$ exists.

Each of our approximating functions $H_{n}$ will be defined in terms of a subdivision $D_{n}$ of $[a, b]$ determined in the following manner. 
Since $\alpha$ is of bounded variation on $[a, b]$ and $H$ is in $\mathrm{OL}^{0}$ then from THEOREM 1 , $\left(I_{H}\right) \int_{a}^{b} H d$ exists and there is a subdivision $k_{n}$ of $[a, b]$ such that if $K^{\prime}=\left\{x_{i}\right\}_{i=1}^{m}$ 1s a refinement of $K_{n}$, then $\left|\left(I_{H}\right) \int_{a}^{b} H d \alpha-\sum_{K^{\prime}} H\left(r_{i}, s_{i}\right) \Delta \alpha_{i}\right|<\frac{1}{n}$ where for $0<i \leq m$, $x_{i-1}<r_{i}<s_{i}<x_{i}$. It follows from the covering theorem and the existence of the limits $\mathrm{H}\left(\mathrm{p}, \mathrm{p}^{+}\right)$and $\mathrm{H}\left(\mathrm{p}^{+} \mathrm{p}^{+}\right)$that there is a subdivision $I_{n}=\left\{\mathrm{x}_{i}\right\}_{i=0}^{\mathrm{m}}$ of $[\mathrm{a}, \mathrm{b}]$ such that if $x_{i-1}<x<r<s<y<x_{i}, 0<i \leq m$, then $|H(x, y)-H(r, s)|<\frac{1}{n}$. Further, let $J_{n}$ denote the set such that $p$ is in $J_{n}$ if $p$ is in $[a, b]$ and $\left|\mathrm{H}\left(\mathrm{p}, \mathrm{p}^{+}\right)-\mathrm{H}\left(\mathrm{p}^{+}, \mathrm{p}^{+}\right)\right| \geq \frac{1}{\mathrm{n}}$ or $\left|\mathrm{H}\left(\mathrm{p}^{-}, \mathrm{p}\right)-\mathrm{H}\left(\mathrm{p}^{-}, \mathrm{p}^{-}\right)\right| \geq \frac{1}{\mathrm{n}}$ and $\mathrm{D}_{\mathrm{n}}=\mathrm{K}_{\mathrm{n}}+\mathrm{J}_{\mathrm{n}}+\mathrm{I}_{\mathrm{n}}$. For each positive integer $n$, let $H_{n}$ be a function from $R x R$ to $N$ determined by $D_{n}=\left\{x_{i}\right\}_{i=1}^{m}$ in the following manner:

$$
\begin{aligned}
& H_{n}(x, y)=\sum_{i=1}^{m} H\left(r_{i}, s_{i}\right)\left[h\left(x, x_{i}\right)-h\left(x, x_{i-1}\right)\right]+\sum_{i=1}^{m}\left[H\left(x_{i-1}, x_{i-1}^{+}\right)-H\left(r_{i}, s_{i}\right)\right]\left[g\left(x, x_{i}\right)\right] \\
&+\sum_{i=1}^{m}\left[H\left(x_{i}^{-}, x_{i}\right)-H\left(r_{i}, s_{i}\right)\right] g\left(x_{i}, y\right) \\
&-\sum_{i=1}^{m}\left[H\left(x_{i}^{-}, x_{i}\right)-H\left(r_{i}, s_{i}\right)\right] g\left(x, x_{i-1}\right) g\left(x_{i}, y\right)
\end{aligned}
$$

for each $(x, y)$ such that $x_{i-1} \leq x<y \leq x_{i}$, for some $0<i \leq m$, and for each $\left[x_{i-1}, x_{1}\right], 0<i \leq m, x_{i-1}<r_{i}<s_{i}<x_{i}$.

It is evident that $\lim _{n \rightarrow \infty} H_{n}=H$ uniformly on $[a, b]$ for if $\varepsilon>0, \frac{1}{n}<\varepsilon$, $D=D_{n}=\left\{x_{i}\right\}_{i=0}^{m}$, and $x_{p-1}<x<r<s<y<x_{p}$ for some $0<p \leq m$, then $H_{n}\left(x_{p-1}, x_{p}\right)=H\left(x_{p-1}, x_{p}\right), H_{n}\left(x_{0} x_{p}\right)=H\left(x_{1} x_{p}\right), H_{n}\left(x_{p-1}, y\right)=H\left(x_{p-1}, y\right)$, and $H_{n}(x, y)=H(r, s)$. Hence $\lim _{n \rightarrow \infty} H_{n}=H$ uniformly on $[a, b]$.

Since $\lim _{n \rightarrow \infty} H_{n}=H$ uniformly on $[a, b]$, applying THEOREM 2 , we have 


$$
\begin{aligned}
& \mathrm{TH}=\lim _{\mathrm{n} \rightarrow \infty} \mathrm{TH}_{\mathrm{n}} \\
& =\lim _{n \rightarrow \infty} \sum_{D_{n}} H\left(r_{1}, s_{1}\right)\left[\operatorname{TH}\left(\cdot, x_{1}\right)-\operatorname{TH}\left(\cdot, x_{1-1}\right)\right] \\
& +\lim _{n \rightarrow \infty} \sum_{D_{n}}\left[H\left(x_{1-1}, x_{1-1}^{+}\right)-H\left(r_{1}, s_{1}\right)\right] T_{g}\left(\cdot, x_{1-1}\right) \\
& +\lim _{n \rightarrow \infty} \sum_{D_{n}}\left[H\left(x_{i}^{-}, x_{i}\right)-H\left(r_{1}, s_{i}\right)\right] T_{g}\left(x_{1}, \cdot\right) \\
& +\lim _{n \rightarrow \infty}\left[-H\left(x_{i}^{-}, x_{i}\right)+H\left(x_{1} ; s_{1}\right)\right] \mathrm{Fg}\left(\cdot, x_{i-1}\right) g\left(x_{1}, \cdot\right) \\
& =\left(I_{\#}\right) \int_{a}^{b} H d \alpha+\sum_{i=1}^{\infty}\left[H\left(x_{i-1}, x_{i-1}^{+}\right)-H\left(x_{i-1}^{+}, x_{i-1}^{+}\right] \beta\left(x_{i-1}\right)\right. \\
& +\sum_{i=1}^{\infty}\left[H\left(x_{i}^{-}, x_{i}\right)-H\left(x_{i}^{-}, x_{i}^{-}\right)\right] \gamma\left(x_{i}\right) \\
& +\sum_{i=1}^{\infty}\left[H\left(x_{i}^{-}, x_{1}^{-}\right)-H\left(x_{i}^{-}, x_{1}\right)\right] \emptyset\left(x_{1-1}, x_{1}\right) \\
& \pm \sum_{i=1}^{\infty} H\left(x_{i}^{-}, x_{1}\right)-H\left(x_{i}^{-}, x_{i}^{-}\right) \Theta\left(x_{i-1}, x_{1}\right)
\end{aligned}
$$

where the existence of each of the infinite sums is assured by LEMMA 3 and the equality of the last two expressions follows from the definition of $D_{n}$.

Al1 that remains to complete the proof of THEOREM 3 is to show that $I_{H} \int_{a}^{b} H d \alpha$ may be represented by $(I) \int_{a}^{b} f_{H} d$ where $f_{H}$ is a function from $R$ to $N$. If we let $f_{H}$ be the function such that for each $p$ in $[a, b] f_{H}(p)=H\left(p^{+}, p^{+}\right)$then $1 t$ follows that (I) $\int_{a}^{b} \mathrm{f}_{H} \mathrm{d \alpha}$ exists and is $\left(I_{H}\right)_{a}^{j b} \mathrm{Hd} \alpha$. 


\section{REFERENCES}

1. Goffman, Casper and Pedrick, George, First Course in Functional Analysis, Prentice-Ha11, Inc., 1965.

2. Helton, B.W. A Product Integral Representation for a Gronwall Inequality, Bulletin of A.M.S. 23 (3), (1969) 493-500.

3. Hildebrandt, T.H. Linear Functional Transformations in General Spaces, Bulletin of A.M.S. 37 (1931) 185-212.

4. Hildebrandt, T.H. and Schoenberg, I.J. On Linear Functional Operations and the Moment Problem for a Finite Interval in One or Several Variables, Annals of Math. 34 (1933) 317-328.

5. Kalterborn, H.S. Linear Functional Operations on Functions Having Discontinuities of the First Kind, Bulletin of A.M.S. 40 (1934), 702-708.

6. Riesz, F. Annales de 1 École, Normale Siperieure (3), 31 (1914).

7. Riesz, F. and B. St.-Nagy Lecons d'analyse fonctionelle, 3rd edition, Budapest: Akademiai Kiado (1955). 


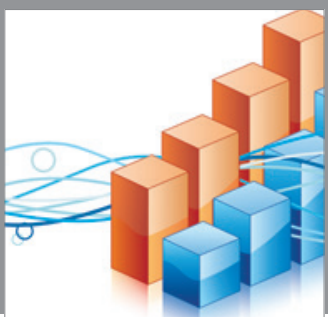

Advances in

Operations Research

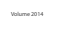

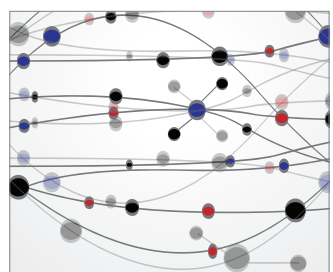

\section{The Scientific} World Journal
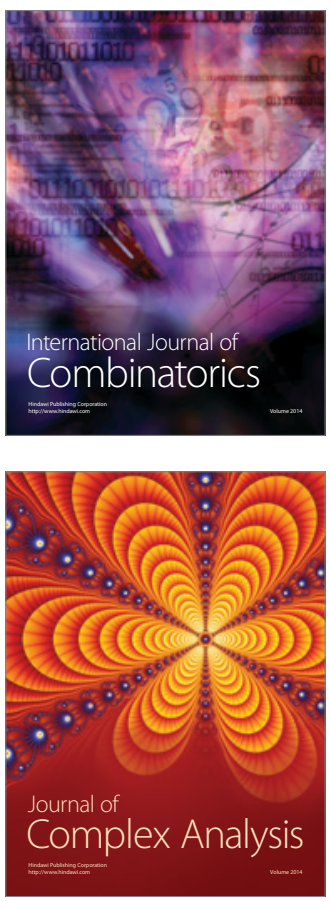

International Journal of

Mathematics and

Mathematical

Sciences
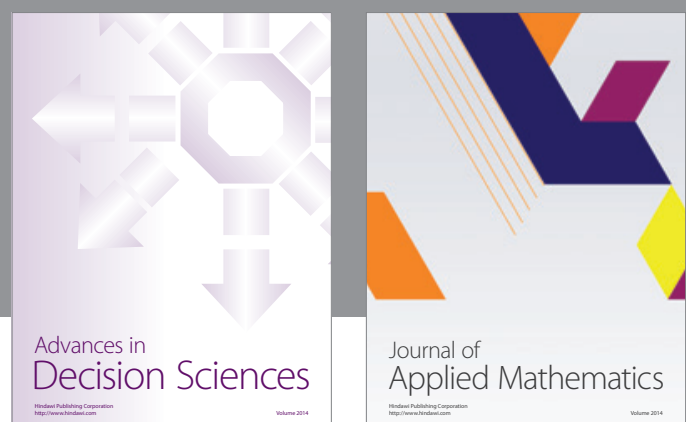

Journal of

Applied Mathematics
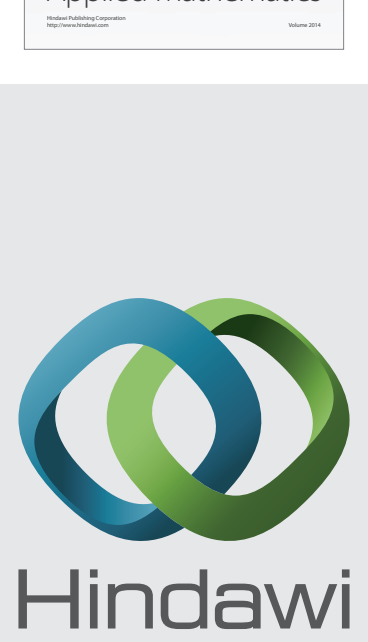

Submit your manuscripts at http://www.hindawi.com
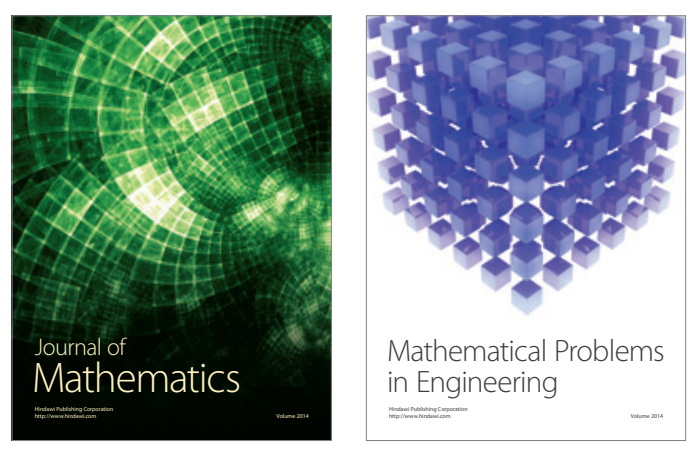

Mathematical Problems in Engineering
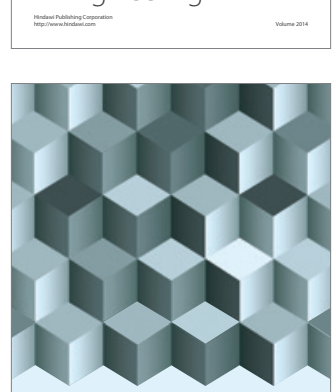

Journal of

Function Spaces
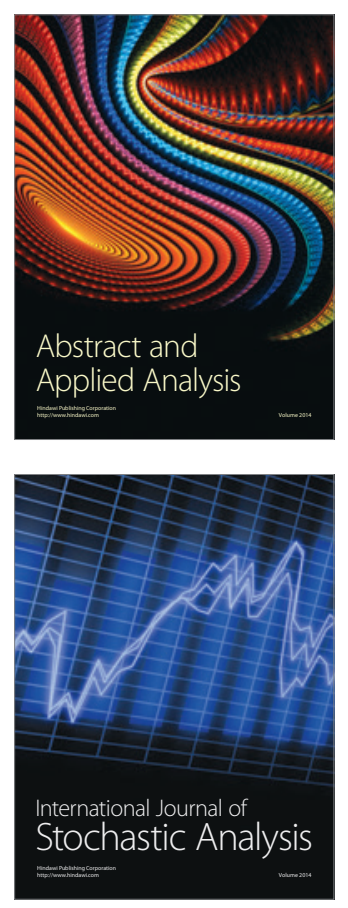

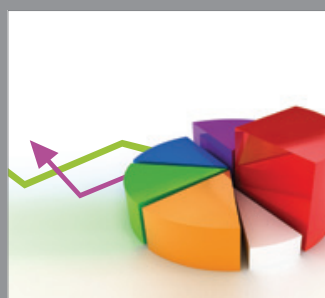

ournal of

Probability and Statistics

Promensencen
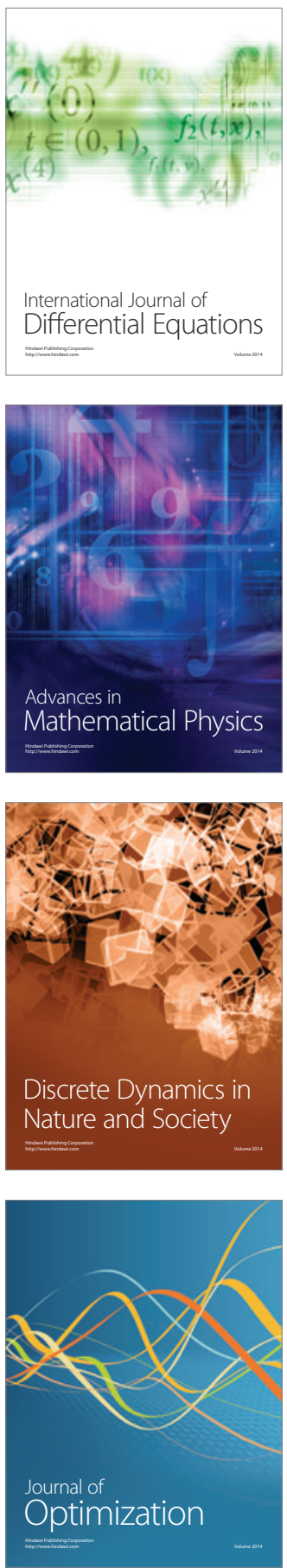